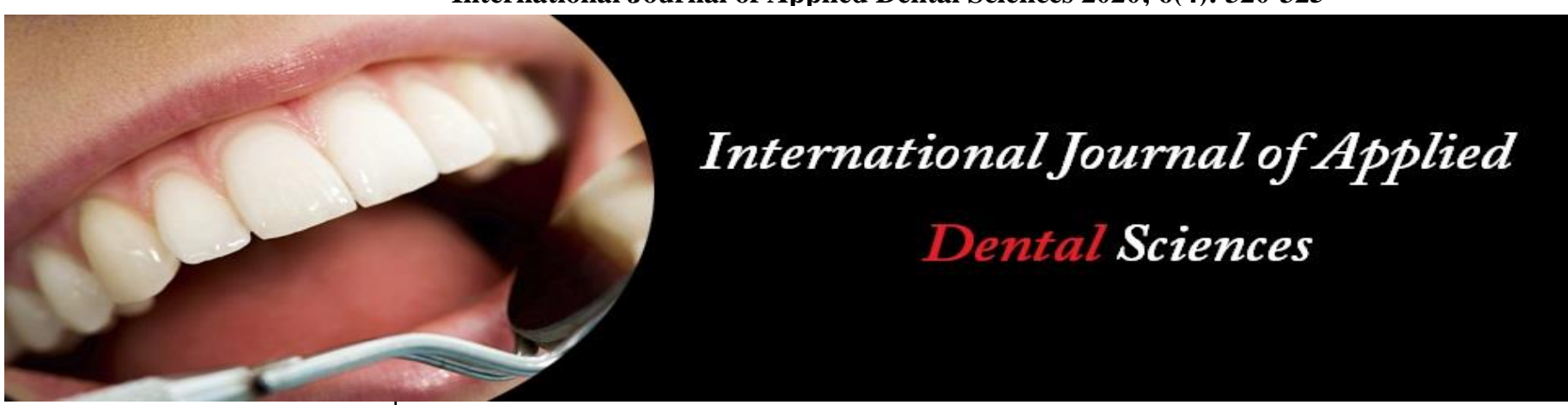

ISSN Print: 2394-7489

ISSN Online: 2394-7497

IJADS 2020; 6(4): 320-325

(C) 2020 IJADS

www.oraljournal.com

Received: 13-08-2020

Accepted: 19-09-2020

\section{Dr. Anju Rana}

Senior Resident, Department of

Periodontics, Maulana Azad

Institute of Dental Sciences,

BS Zafar Marg, New Delhi, India

Dr. Arundeep Kaur

Professor and Head, Department

of Periodontics, Maulana Azad

Institute of Dental Sciences,

BS Zafar Marg, New Delhi, India

\section{Dr. Farrukh Faraz}

Associate Professor, Department of Periodontics, Maulana Azad

Institute of Dental Sciences,

BS Zafar Marg, New Delhi, India

\section{Dr. Shruti Tandon}

Associate Professor, Department of Periodontics, Maulana Azad Institute of Dental Sciences,

BS Zafar Marg, New Delhi, India

Corresponding Author:

Dr. Anju Rana

Senior Resident, Department of

Periodontics, Maulana Azad

Institute of Dental Sciences,

BS Zafar Marg, New Delhi, India

\section{COVID-19 killer/curb: Challenges v/s measures in dentistry}

\section{Dr. Anju Rana, Dr. Arundeep Kaur, Dr. Farrukh Faraz and Dr. Shruti Tandon}

DOI: $\underline{\text { https://doi.org/10.22271/oral.2020.v6.i4e.1085 }}$

\section{Abstract}

The global outbreak of the newly identified virus COVID-19 has led to various challenges in the field of the healthcare department. Today this silent killer has claimed several deaths all over the world. Research work has been accelerated in the field of diagnosis, vaccines, and therapeutics to curb the contagious transmission of this virus. Dental professionals and dental care settings invariably carry a higher risk of transmission due to the specificity of dental procedures which involve face-to-face communication with patients and frequent exposure to saliva, blood, and other body fluids. Thus, this article is based on the latest guidelines and ongoing research on COVID-19 along with strictly recommended measures and management protocols for dentists in their private practices and dental institutions.

Keywords: Novel Coronavirus 2019, COVID-19, Healthcare professionals, Dentist

\section{Introduction}

Sudden onset of reports of pneumonia of unknown etiology from Wuhan city, Hubei province of China has gained global attention. The pathogen causing this infection has been classified by the World Health Organization (WHO) as Corona Virus Disease 2019/ 2019 novel coronavirus (Covid-19). On 30 ${ }^{\text {th }}$ January 2020, WHO declared the outbreak of Covid-19, a Public Health Emergency of International Concern. Initially starting from few cases restricted to china, today it has crossed more than a million cases worldwide. On $11^{\text {th }}$ March 2020, Covid-19 outbreak was declared as a pandemic disease. Today its diagnosis is based on RTPCR analysis and RAT test. Efforts are still ongoing to develop quick and sensitive diagnostic aids and vaccines to bring a halt to this pandemic. The fact that aerosols and droplets are considered as the main spread routes, awareness along with updated knowledge among dental professionals and its team is very essential. Worldwide around $14 \%-35 \%$ cases reported to WHO is among healthcare workers. However, due to limited qualitative data available, it is still not clear the number of dentists involved. This article is mainly based on various measures and precautions to be taken by dental professionals while performing dentistry.

\section{Characteristics of novel coronavirus}

Coronavirus belongs to the Coronaviridae family characterized by large single-stranded RNA genome ${ }^{[1]}$. Presently, there are four generations of coronaviruses which include $\alpha \mathrm{CoV}, \beta-\mathrm{CoV}$, $\gamma-\mathrm{CoV}$, and $\delta-\mathrm{CoV}$ causing infectious diseases in humans and vertebrates ${ }^{[2]}$. Out of these, covid $\alpha$ and Covid $\beta$ mainly infect the respiratory, gastrointestinal, and central nervous systems. According to the phylogenetic analysis based on the viral genome, Covid-19 has been categorized under the group of $\beta-\mathrm{CoV}$. It owns a typical coronavirus structure with "spike-like protein" in the membrane envelope, along with other polyproteins, nucleoproteins, and membrane proteins, such as RNA psolymerase, helicase, 3-chymotrypsin-like protease, glycoprotein, papain-like protease, and accessory proteins ${ }^{[3,4]}$. The $\mathrm{S}$ protein existing in coronavirus can bind to the host receptors mainly the human angiotensin-converting enzyme II (ACE2), to help the entry of the virus into the target cells ${ }^{[5]}$. The higher affinity between ACE2 and Covid-19 S protein suggested that the population with higher expression of ACE2 might be more susceptible to this virus. 


\section{Probable transmission routes of covid-19 in dental clinics}

The common transmission routes of novel coronavirus include contact transmission, droplet transmission, and aerosols transmission. ${ }^{[6]}$ Contact is the most common mode of transmission. Contact may be direct or indirect. Direct transmission occurs when infectious agents are transferred from one person to another via cough, sneeze, and droplet inhalation. Indirect transmission involves the transfer of an infectious agent through contaminated instruments, and surrounding surfaces via hands to eyes, nasal, or oral mucous membrane ${ }^{[6,7]}$. Although common clinical manifestations of novel coronavirus infection do not include eye symptoms or oral findings, studies have shown that Covid-19 is not only limited to the respiratory tract and that the eye and oral mucous membrane provides an effective pathway for entry of the virus in the host body ${ }^{[8]}$. Droplets can be transmitted directly or indirectly to mucosal surfaces via hands whereas infectious aerosols can be dispersed over long distances by air currents through ventilation or air-conditioning systems and inhaled by the susceptible individuals who have not had any contact with the infectious person causing infection.

The incubation period for infected individuals with Covid-19 has been reported to be approximately 14 days. Also when symptomatic individuals were reported after 24 days, it was confirmed that they can act as a carrier of this contagious virus ${ }^{[9,10]}$. To et al. reported that the live viruses were present in the saliva of infected individuals ${ }^{[8]}$. Xu et al. reported high expression of ACE2 receptor of Covid-19 on the epithelial cells of oral mucosa especially in epithelial cells of tongue indicating oral cavity as a potentially high-risk route of Covid-19infection ${ }^{[11]}$. While performing routine dental procedures as it is hard to avoid the generation of a large amounts of aerosols and droplets mixed with a patient's saliva and even blood, makes it the most critical concern today. In addition to this when the infected patient cough along with the routine use of high-speed dental hand pieces, air-rotors and ultrasonic scalers lead to an additional aerosols production. Also droplets and aerosols are small enough to stay airborne for an extended period before they settle on the surrounding surfaces leading to another challenge for a dental professional.

\section{Effective infection control measures in dental practice}

Various general measures have been already taken by the National Centre for Disease Control (NCDC) and the Ministry of Health and Family Welfare (MoHFW), Government of India. WHO Country office for India (WCO) has been working with NCDC, Indian Council of Medical Research (ICMR), and Ministry of Information and Broadcasting on disease surveillance, laboratory testing capacity and vaccines, and on risk communications. In spite of these measures, combined extra efforts are required to combat this historic public health emergency.

The dentist should have a proper training and should use adequate personal protective equipment (PPEs) to prevent any transmission ${ }^{[11]}$. When patients are in an incubation period or unaware of their infection (asymptomatic individuals) or choose to hide their infection, smart efforts with caution are recommended. National Guidelines for Infection Prevention and Control in Healthcare Facilities 2020 have recommended standard precautions and transmission-based precautions. The key components of standard precautions are hand hygiene, personal protective equipment (PPEs), respiratory hygiene and cough etiquette, prevention of injuries from sharps, safe handling of patient care equipment, principles of asepsis and environmental infection control ${ }^{[12]}$. Along with these universal precautions, extra-measures should be taken starting from the outpatient department (OPD) screening, before examining patients, during routine dental procedures and during waste management and disinfection.

\section{Measures during outpatient department (OPD) screening}

Firstly, the patient's body temperature should be measured using a contact-free forehead thermometer (Non-Contact Infrared Digital Thermometer). Dental clinics and hospitals are recommended to measure and record the temperature of every staff and patient as a routine procedure. In the most accessible area of OPD, posters (in local language) should be displayed to spread awareness for Covid-19 and its symptoms among patients ${ }^{[13]}$. Patients are requested to give their phone numbers and addresses at the reception to contact them in the future if any of the patients or staff is diagnosed with Covid19. Case investigating form should be kept at the reception areas and patients should be asked to fill this form prior to entering for a dental examination. Online consultations should be given preference compared to face to face interactions. Patients who have scheduled an appointment with a dentist should be screened first for any symptoms on telephonic conversations.

\section{Measures before examining patients}

Based on guidelines issued by NCDC, a patient with COVID19 who is in the acute febrile phase of the disease is not recommended to visit the dental clinic ${ }^{[11]}$. Still, if this does occur, the dental professional should be able to provide required emergency treatment with minimum exposure time ( $<20$ minutes).

Patients along with their belongings and family members are asked to stay outside in the reception area. Patient hands are sanitized and asked to remove footwear or given shoe covers before entering the clinical area. Fingertip pulse oximeter is used to record the arterial blood oxygen saturation level of the patient. A disposable full-length drape is placed on the patient with their hands tucked in after the patient sits on the dental chair.

Now, the patient is asked to remove his mouth mask. A preoperative mouth rinse before examination and dental procedure is generally believed to decrease the microbial load including the viral load. As Covid-19 is vulnerable to oxidation therefore pre-procedural mouth rinse $(0.2 \%$ povidine-iodine or $1.5 \%$ hydrogen peroxide) for 30 seconds to 1 minute is recommended.

\section{Measures while examining patients and performing routine dental procedures}

A routine dental practice should be suspended according to the situation of epidemics. Avoid all elective procedures and only emergency treatment like access opening or abscess drainage should be done only under extra protection. Implementing four-handed dentistry is advised. Based on the possibility of the spread of Covid-19, three-level protective measures are recommended ${ }^{[14]}$. The primary protection (standard protection for staff in clinical settings), secondary protection (advanced protection for dental professionals), and tertiary protection (strengthened protection when contact patient with suspected or confirmed Covid-19 infection).

Although proper hand hygiene is the routine prerequisite for a dental practice, hand washing compliance is relatively low, which imposes a greater challenge to infection control. Reinforcement for good hand hygiene is of extreme 
importance. WHO has proposed five moments of hand hygiene in clinical settings. Specifically, the dental professionals should wash their hands before patient examination, before dental procedures, after touching the patient, after touching the surroundings and equipment without disinfection, and after touching the oral mucosa, saliva, blood, body fluids, and secretion ${ }^{[15]}$. Also, care should be taken after touching the patient's documentation and the dentist should avoid touching their own eyes, nose, and mouth. The WHO guidelines on hand hygiene (6 steps) recommended that the duration of the entire procedure should be 40-60 seconds for hand washing ${ }^{[15]}$ (Fig. 1) and 20-30 seconds while using alcohol-based hand rub (ABHR) ${ }^{[16]}$ (Fig. 2).

\section{How to Handwash?}

\section{WASH HANDS WHEN VISIBLY SOILED! OTHERWISE, USE HANDRUB}

\section{(1) Duration of the entire procedure: $40-60$ seconds}

0

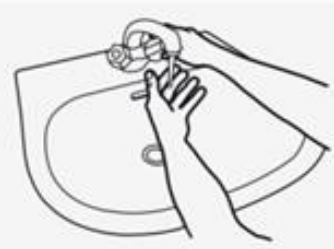

Wet hands with water;
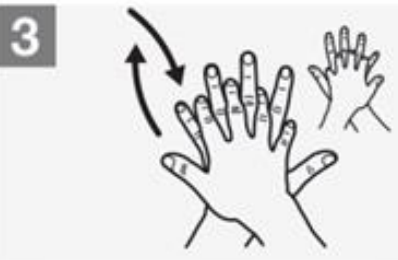

Right palm over left dorsum with interlaced fingers and vice versa;

6

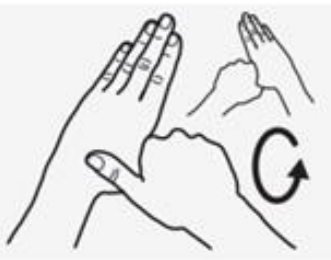

Rotational rubbing of left thumb clasped in right palm and vice versa;

9

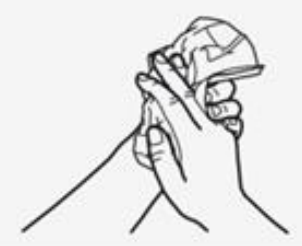

Dry hands thoroughly with a single use towel;
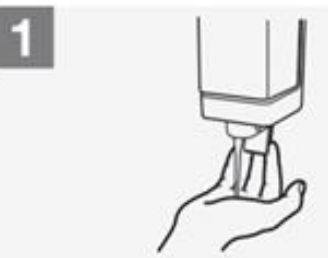

Apply enough soap to cover all hand surfaces;

\section{4}

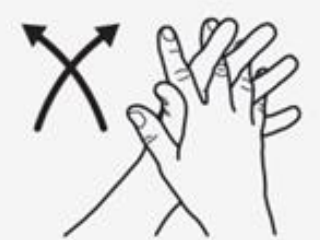

Palm to palm with fingers interlaced;
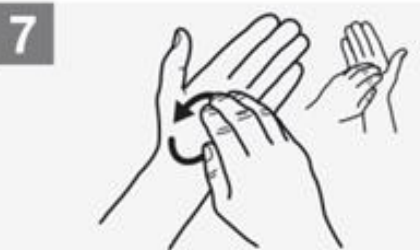

Rotational rubbing, backwards and forwards with clasped fingers of right hand in left palm and vice versa;
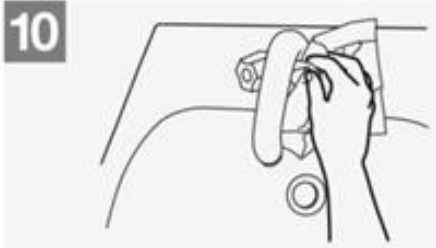

Use towel to turn off faucet;
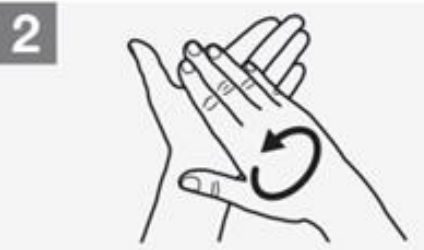

Rub hands palm to palm;

5

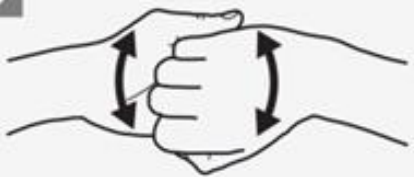

Backs of fingers to opposing palms with fingers interlocked;

8

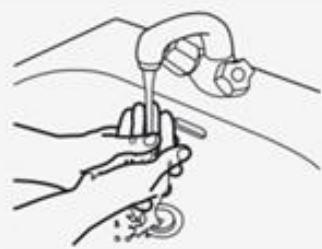

Rinse hands with water;
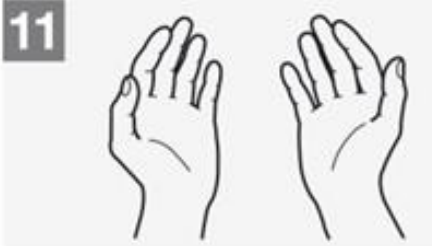

Your hands are now safe.

Fig 1: WHO Guidelines and steps how to hand wash. 


\section{How to Handrub?}

\section{RUB HANDS FOR HAND HYGIENE! WASH HANDS WHEN VISIBLY SOILED}

(1) Duration of the entire procedure: $20-30$ seconds

1 a

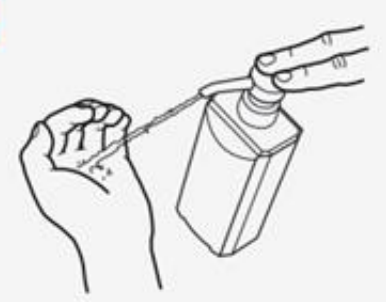

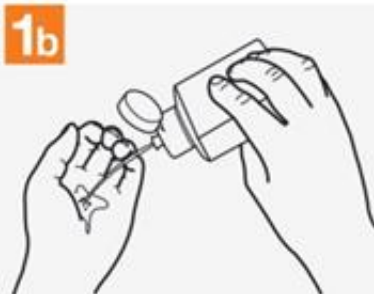

Apply a palmful of the product in a cupped hand, covering all surfaces;

3

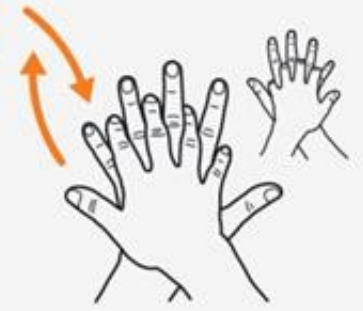

Right palm over left dorsum with interlaced fingers and vice versa;
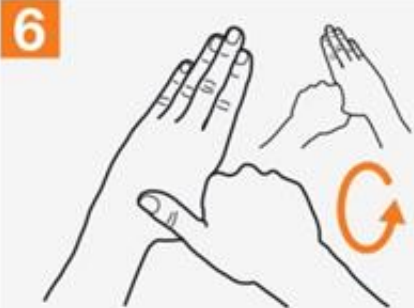

Rotational rubbing of left thumb clasped in right palm and vice versa;
4

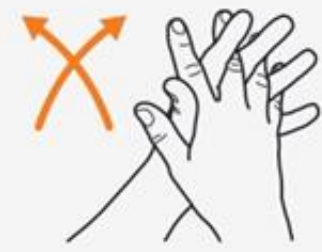

Palm to palm with fingers interlaced;

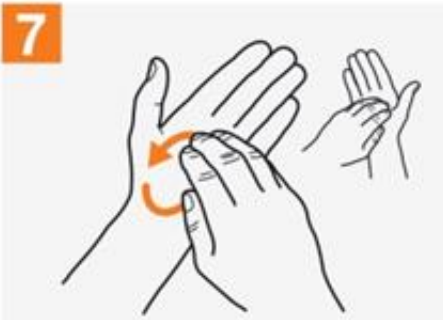

Rotational rubbing, backwards and forwards with clasped fingers of right hand in left palm and vice versa;

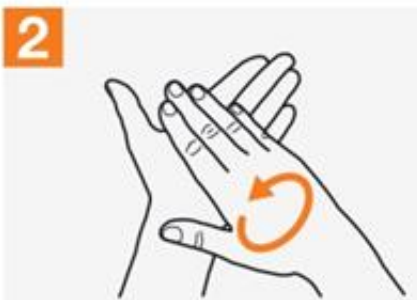

Rub hands palm to palm;
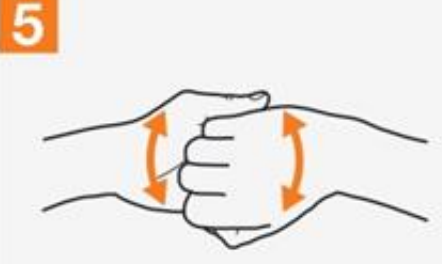

Backs of fingers to opposing palms with fingers interlocked;

8

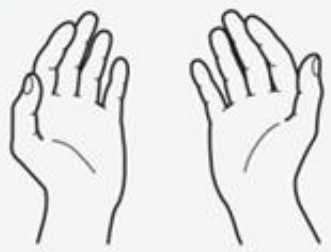

Once dry, your hands are safe.

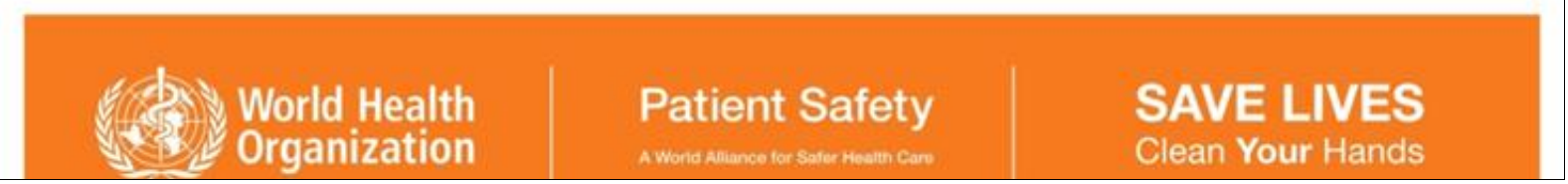

Fig 2: WHO Guidelines and steps how to hand rub

Special work clothes or clinical scrubs and work shoes should be worn by the dentist. The proper donning sequence of PPE should be followed while performing any aerosol procedure. Before donning, perform complete hand hygiene using soap and water. Start donning with disposable surgical cap, followed by a medical protective mask (N95) and surgical mask. Then, wear inner disposable nitrile/latex gloves followed by goggles and face shield. Finally, put on protective clothing/ hazmat suit along with shoe covers. Now, put on outer disposable latex gloves. A surgical mouth mask worn over N95 should be changed after every patient.

While doffing off PPE, wash hands and remove visible bodily fluids/ blood contaminants on the outer surfaces of both hands. Then, remove outer gloves, perform hand hygiene, and wear a new pair of examination/ latex gloves. Remove disposable gown (rolling inward-out direction) along with outer gloves and waterproof boots covers. Again perform hand hygiene and remove face shield followed by goggles, mask, head cap, and inner disposable gloves. Strictly perform hand hygiene (alcohol-based scrub) at each step of doffing off 
PPE. At last, again perform hand hygiene and put on clean clothes after a shower if possible. Donning and doffing of PPE should be strictly done in two separate designated rooms only.

During dental procedures, the use of a rubber dams is recommended to decrease the salivary and bloodcontaminated aerosols production. It has been documented that the use of rubber dam could significantly reduce airborne particles in an area of approximately 3 -foot diameter of the operational field by $70 \%{ }^{[17]}$. Extra high-volume suctions along with the regular suction are recommended ${ }^{[18]}$. Effective minimally invasive alternate methods are recommended like manual devices (Carisolv) for caries removal and hand scalers for periodontal scaling. The high-speed dental hand piece without anti-retraction valves may aspirate and eject the debris and fluids during the procedures therefore especially designed anti-retraction hand pieces having anti-reflux/antiretractive valves are suggested to prevent cross-infection ${ }^{[11,}$ 18]. In-between, patient's surroundings and dental chair disinfection should be strictly followed. Intraoral radiographs should be avoided and if required panoramic radiographs (OPG) or cone-beam CT is advised.

\section{Measures during waste management and disinfection}

Biomedical waste segregation guidelines should be followed and the clinic settings should be disinfected according to the protocol for the management of Surface Cleaning and Disinfection of Medical Environment released by the Infection Prevention and Control in Healthcare Facilities 2020, NCDC, and Govt. of India.

All PPEs such as eye wears/goggles, face shields, splashproof apron, plastic cover all, hazmat suit, nitrile gloves should be collected in the red bag whereas used masks (triplelayered mask, N95 mask), head cap, shoe-cover, disposable gown (Non-plastic) should be collected in yellow bags. Biomedical waste should be segregated into double-layered bag and sealed with cable ties in a gooseneck fashion. Finally, it is sprayed with $1 \%$ sodium hypochlorite solution. All sharp wastes should be collected into a sharp puncture-proof container, sealed and, sprayed with $1 \%$ sodium hypochlorite solution. Affix label and transfer BMW to the storage room. Spray bins with $1 \%$ sodium hypochlorite solution after emptying its contents. Records of all BMW should be maintained on daily basis.

Patient turn-over protocol includes chair disinfection, filling of $0.01 \%$ sodium hypochlorite solution in the water inlet bottle of the dental chair to flush out all water outlets like 3way syringe, ultrasonic scalers and air rotors for 30-40 seconds. All hand instruments are rinsed in running water and dipped into 5\% BIB Forte solution for 30 minutes.

The fumigation should be done on daily basis in clinical or high contact areas or after any aerosol producing procedure and biweekly in non-clinical or low contact areas. Before the fumigation, seal the area/room completely. Prepare fumigation solution by adding $7.5 \mathrm{ml}$ of fumigation chemical in 1 liter of water. Place fumigation machine at one corner of the room and leave it for 30 minutes.

It has been shown that at room temperature, $\mathrm{HCoV}$ remains infectious up to 9 days and persists better at $50 \%$ relative humidity compared with $30 \%$ relative humidity. Thus, keeping a clean and dry environment in the dental office could help decrease the persistence of Covid-19 ${ }^{[19]}$. Public areas and appliances should also be frequently cleaned and disinfected, including door handles, chairs and desks. The elevator should be disinfected regularly. Lastly, medical waste and domestic waste generated by the treatment of patients with suspected Covid-19 infection (including disposable protective equipment after use) should be transported timely and disposed according to Hospital Infection Prevention and Control Guidelines ${ }^{[8]}$.

\section{Conclusion}

During the global pandemic of Covid-19, infection prevention and control measures should be strictly followed without any negligence. The primary and most critical goal is to halt its transmission. Therefore, strict adherence to universal standard protocols help in protecting dental professionals as well as patients from transmission of infection. Strict and proper use of personal protective equipment (while doffing), proper hand hygiene instructions, and routinely use of N-95 masks authenticated by the National Institute for Occupational Safety and Health are advised. Use of alcohol-based hand rubs, everyday fumigation, and proper management of medical waste are recommended. Thus, implementing these safe and smart work practices will help us to curb the pandemic phase of Covid-19 soon.

\section{References}

1. Fehr AR, Perlman S. Coronaviruses: an overview of their replication and pathogenesis. Methods Mol Biol 2015;1282:1-23.

2. Fan Y, Zhao K, Shi ZL, Zhou P. Bat coronaviruses in China. Viruses 2019;11:210.

3. Jin Y, Cai L, Cheng Z. A rapid advice guideline for the diagnosis and treatment of 2019 novel coronavirus (2019$\mathrm{nCoV}$ ) infected pneumonia (standard version). Military Med Res 2020,7. https://doi.org/10.1186/s40779-0200233-6.

4. Li F. Structure, function, and evolution of coronavirus spike proteins. Annu Rev Virol 2016;3:237-61.

5. Hantak MP, Qing E, Earnest JT, Gallagher T. Tetraspanins: architects of viral entry and exit platforms. J Virol 2019;93:e01429-e17.

6. Tian X, Li C, Huang A, Xia S, Lu S, Shi Z et al. Potent binding of 2019 novel coronavirus spike protein by a SARS coronavirus-specific human monoclonal antibody. Emerg Microbes Infect 2020;9:382-5. (doi: 10.1080/22221751.2020.1729069).

7. Lu CW, Liu XF, Jia ZF. 2019-nCoV transmission through the ocular surface must not be ignored. The Lancet 2020. https://doi.org/10.1016/S01406736(20)30313-5

8. To KK-W, Tsang OT-Y, Yip CC-Y, Chan K-H, Wu T-C, Chan JM-C et al. Consistent detection of 2019 novel coronavirus in saliva. Clin Infect Diseases 2020,149. (https://doi.org/10.1093/cid/ciaa149).

9. Huang C, Wang Y, Li X, Ren L, Zhao J, Hu Y et al. Clinical features of patients infected with 2019 novel coronavirus in Wuhan, China. Lancet 2020;395:497-506.

10. Backer JA, Klinkenberg D, Wallinga J. Incubation period of 2019 novel coronavirus (2019-nCoV) infections among travellers from Wuhan, China, 20-28 January 2020. Euro Surveill https://doiorg/102807/15607917Es20202552000062 2020.

11. Xu H, Zhong L, Deng J, Peng J, Dan H, Zeng X, et al. High expression of ACE2 receptor of 2019-nCoV on the epithelial cells of oral mucosa. Int. J Oral Sci 2020,12. (https://doi.org/10.1038/s41368-020-0074-x).

12. Wei J, Li Y. Airborne spread of infectious agents in the indoor environment. Am J Infect Control 2016;44:S102- 
S8.

13. National Centre for Disease Control, Ministry of Health and Family Welfare, Government of India; Novel Corona Virus 2020. OPD display (https://ncdc.gov.in/WriteReadData/1892s/471384024115 80717944.pdf).

14. Meng L, Hua F, Bian Z. Coronavirus Disease 2019 (COVID-19): Emerging and Future Challenges for Dental and Oral Medicine. J Dent Res 2020. doi: 10.1177/0022034520914246

15. WHO. WHO guidelines on hand hygiene in health care 2009.

16. WHO. How to hand wash? Poster (https://www.who.int/gpsc/5may/How_To_HandWash_P oster.pdf?ua=1)

17. Samaranayake LP, Reid J, Evans D. The efficacy of rubber dam isolation in reducing atmospheric bacterial contamination. ASDC J Dent Child 1989;56:442-4.

18. Samaranayake LP, Peiris M. Severe acute respiratory syndrome and dentistry: a retrospective view. J Am Dent Assoc 2004;135:1292-302.

19. Otter JA, Donskey C, Yezli S, Douthwaite S, Goldenberg SD, Weber DJ. Transmission of SARS and MERS coronaviruses and influenza virus in healthcare settings: the possible role of dry surface contamination. J Hosp Infect 2016;92:235-50. (doi: 10.1016/j.jhin.2015.08.027). 